\title{
Correspondence
}

\section{Single dose medication}

To the Editor:

The authors of "Single dose medication vial packaging deficiencies"' are to be congratulated for their pursuit of this problem.

While statements about the "responsibility of the end user"' may provide legal cover, such an artitude does not enhance safety. Practitioners bear responsibility but it is naive to expect products will always be used under optimum conditions. Practitioners will mistakenly use single dose products on more than one patient, if presented with a vial not clearly labeled or designed such that it appears not to have been used. Misuse is particularly likely if practitioners are carrying out several tasks at once, tired, or distracted. Errors will occur when the "limits of the brain's information processing capacity are reached". It is pointless to blame the individual. ${ }^{2}$

Manufacturers must make products that are safe not only when used by alert individuals working in optimum conditions. They should anticipate "factors that provide the conditions in which errors occur", ${ }^{3}$ those worst case, error producing conditions. Single dose vials systems must be engineered to maximize safety at each stage of patient care:

a) reducing the chance of error occurring, (i.e., the anesthesiologist choosing a particular vial) through clear labeling of vials as single dose products;

b) trapping the error as it occurs (i.e., the anesthesiologist using that particular vial) - by designing vials so that previous entry will be obvious; and

c) minimizing the consequences of the error - by monitoring for adverse incidents. ${ }^{4}$

Patients and practitioners need and deserve such a system.

J.M. Davies MSC MD FRCPC

Calgary, Alberta

C.A. Vincent MPHIL PHD

Clinical Risk Unit

University College London

London, England

\section{REFERENCES}

1 Craig DB, Martens DJ, Embil JM. Single dose medication vial packaging deficiencies. Can J Anaesth 1998; 45: 501-8.
2 Vincent $C A$. Risk, safety and the dark side of quality. BMJ 1997; 314: 1775-6.

3 Reason J. Understanding adverse effects: human factors. In: Vincent CA (Ed.). Clinical Risk Management. London: BMJ Publishing Group, 1995: 31-54.

4 Davies J.M. Risk assessment and risk management in anaesthesia. In: Aitkenhead AR (Ed.). Quality Assurance and Risk Management in Anesthesia. Bailliere's Clinical Anaesthesiology International Practice and Research. London: Bailliere Tindal, 1996; 10: 357-72.

\section{Prevention of succinylcholine fascicula- tions}

To the Editor:

The title of an article is crafted to entice readers to read the text below. One of the minimum requirements is that it be correct and correlate to the article. Imagine my surprise when reading the conclusion to the article titled "Rocuronium is the best nondepolarizing relaxant to prevent succinylcholine fasciculation and myalgia." One can only conclude rocuronium pre-treatment reduces muscle pain after succinylcholine administration. However, the conclusion of the article is that rocuronium pre-treatment does not reduce succinylcholine myalgia when compared with the control group. At the very least it is the responsibility of reviewers and authors to make sure the title is reflective of the article's content and conclusion.

Fred Mensink MD FRCPC

Calgary General Hospital

Calgary, Alberta

\section{REFERENCE}

1 Martin R, Carrier J, Pirlet M, Claprood Y, Tétrault J-P. Rocuronium is the best non-depolarizing relaxant to prevent succinylcholine fasciculations and myalgia. Can J Anaesth 1998; 45: 521-5.

To the Editor:

The recent paper by Martin $e t a l^{1}$ on the efficacy of various nondepolarizing relaxants in preventing succinylcholine-induced fasciculations includes some statements that require comment.

1. The statement that the doses employed approximated $10 \%$ of the "intubating dose" implies that 